\title{
A leitura da capa do livro Brincando de inventar na perspectiva da gramática do design visual
}

\section{Reading the Cover of the Book Brincando de Inventar in the Perspective of Grammar of Visual Design}

Sammya Santos Araújo*

*Universidade do Porto, Porto / Portugal

sammyaletras@hotmail.com

https://orcid.org/0000-0002-6659-2905

Lya Oliveira da Silva Souza Parente**

**Universidade Estadual do Ceará (UECE), Fortaleza, Ceará / Brasil

lya.loss@gmail.com

https://orcid.org/0000-0003-2548-6206

Antonia Dilamar Araújo***

***Universidade Estadual do Ceará (UECE), Fortaleza, Ceará / Brasil

dilamar.araújo@uece.br

https://orcid.org/0000-0002-5031-8725

RESUMO: Este trabalho visa analisar, à luz da Gramática do Design Visual proposta por Kress e van Leeuwen (1996), a organização e a composição imagética da capa do livro de literatura infantil Brincando de inventar. O livro selecionado compõe a coleção Paic, prosa e poesia, que é distribuída em todas as escolas do ensino fundamental da rede pública do Ceará. Procuramos compreender de que forma as imagens dialogam para a produção de significados, contribuindo para o processo de alfabetização a partir da leitura imagética e literária. Constatamos que a estrutura narrativa transacional estabelecida no texto multimodal analisado usa de vários recursos para convidar o leitor, que está em fase de alfabetização, a vivenciar a leitura imagética e literária por meio da ludicidade, de modo que este aprenda brincando.

PALAVRAS-CHAVE: multimodalidade; literatura infantil; imagem; gramática do design visual; Paic. 


\begin{abstract}
This paper aims at analyzing, in the light of Grammar of Visual Design proposed by Kress and van Leeuwen (1996), the organization and the imagistic composition of the cover of the children's book Brincando de inventar. The selected book composes the Paic, Prose and Poetry collection, which is distributed in all public elementary schools of Ceará. We try to understand how the images interact for the production of meanings, contributing to the literacy process by means of imagistic and literary reading. We found that the transactional narrative structure established in the analyzed multimodal text uses several resources to invite the reader, who is in the literacy development stage, to experience imagistic and literary reading through playfulness, so that the child learns by playing.
\end{abstract}

KEYWORDS: multimodality; children's literature; image; grammar of visual design; Paic.

\title{
1 Introdução
}

Os problemas envolvendo alfabetização no Brasil não são recentes. Muitas pesquisas já foram realizadas em torno desta temática. Entretanto, desde os anos 1990, o contexto educacional brasileiro vem se modificando e muitas ações e políticas educacionais eficazes vêm traçando um novo caminho para a melhoria dos índices de alfabetização das crianças. Dentre essas políticas, insere-se o Programa Alfabetização na Idade Certa (Paic) (CEARÁ, 2012), iniciado em 2007, pela Secretaria da Educação do Estado do Ceará, com o objetivo de alfabetizar todos os alunos da rede pública de ensino do estado até os sete anos de idade. No ano de 2016, objetivando dar continuidade ao Paic, desta vez garantindo a aprendizagem dos conteúdos fundamentais na Língua Portuguesa e na Matemática para o ensino fundamental da rede pública, foi implantado o Programa de Aprendizagem na Idade Certa (Mais Paic).

Atualmente, o Mais Paic é estruturado em cinco eixos: Educação Infantil; Ensino Fundamental I ( $1^{\circ}$ ao $5^{\circ}$ ano); Literatura e Formação do Leitor; Ensino Fundamental II e Educação Integral; Gestão Municipal; e Avaliação Externa. Na execução das ações do programa os municípios do Estado do Ceará contam com o apoio técnico para o desenvolvimento de uma intervenção sistêmica de gestão, de modo que os recursos e esforços investidos cheguem até a sala de aula e produzam a elevação dos resultados dos níveis de aprendizagem das crianças. Dentre as ações previstas para elevar o nível de proficiência em leitura e escrita dos alunos, encontram-se a produção, a impressão e a dinamização da coleção Paic, prosa e poesia. 
Nos últimos anos, foram impressos e distribuídos 180 livros, totalizando 15 coleções distribuídas para as salas de aula do ensino fundamental I da rede pública de ensino. Assim, percebemos o quanto a literatura infantil está presente no contexto escolar das crianças cearenses. Considerando nosso interesse em literatura infantil, este artigo pretende analisar uma capa de livro da referida coleção, do ano de 2015, buscando compreender como as imagens dialogam na produção e veiculação de significados, com a intenção de fomentar no aluno o interesse pela leitura. O livro escolhido para análise é o Brincando de inventar (CAVALCANTE; OLIVEIRA, 2015), texto de Neomaly Cavalcante e ilustrações de Emanuel Oliveira.

O estudo visa analisar os elementos que compõem a semiótica visual da capa desse livro de literatura infantil, utilizando como base o referencial teórico de Kress e van Leeuwen (1996) na aplicação da análise do sistema semiótico de imagens. A análise de um texto multimodal é um processo complexo, pois abrange diferentes modos de significação e uma multiplicidade de elementos, que constroem um universo sociocultural.

Nas próximas seções, contextualizaremos como surgiu a referida coleção e a presença das ilustrações na mesma; abordaremos o referencial teórico com as categorizações em que nos ancoramos; e apresentaremos as discussões geradas pela análise da capa, as considerações finais e as referências bibliográficas.

\section{As ilustrações na coleção Paic, prosa e poesia}

A coleção Paic, prosa e poesia surgiu com o objetivo de investir na produção local e viabilizar a presença da temática regional nos livros, com textos que retratam, muitas vezes, o contexto vivido pelas crianças cearenses. Inicialmente, no ano de 2009, a Secretaria da Educação do Ceará convidou alguns autores do estado para escrever textos infantis para o Paic. Estes textos foram editados em duas coleções de 12 livros cada, uma destinada a crianças de até seis anos e outra a crianças de sete e oito anos de idade; criava-se assim um material relacionado com a realidade dos novos leitores e representativo da cultura do estado. Nos anos seguintes, foram realizados processos seletivos para a escolha de novos textos que seriam diagramados e ilustrados pela Secretaria da Educação (Seduc) do referido estado. Até o ano de 2017, foram realizados seis processos, com 180 livros selecionados. 
Vale ressaltar que os processos seletivos revelaram novos talentos que muitas vezes não tiveram oportunidade de mostrar seus textos para as editoras, por estas preferirem dar visibilidade a autores já consagrados no ramo editorial. Para a escolha dos textos que fizeram parte da coleção analisada, foram convidados especialistas (mestres e doutores) e ilustradores que possuem uma larga experiência na área da literatura infantil. Portanto, observa-se que no decorrer dos anos, há uma renovação de livros nos Cantinhos de leitura, denominado pelo programa como um espaço físico reservado em sala de aula dedicado para a exposição do acervo literário infantil.

Atualmente, a coleção atende a turmas da educação infantil até o $5^{\circ}$ ano do ensino fundamental e está dividida em categorias: 1 - turmas da educação infantil; 2 - turmas $1^{\circ}$ e $2^{\circ}$; e 3 - turmas do $3^{\circ}, 4^{\circ}$ e $5^{\circ}$ anos. Cada categoria é composta de 12 títulos, totalizando 36 na coleção. Os livros que compõem cada categoria ressaltam e valorizam as ilustrações, dialogando com o texto.

Oliveira (2008) afirma que um livro de literatura para crianças pequenas, em fase inicial de escolarização, necessita ser visualmente atraente, com boas ilustrações e bem coloridas. Assim, as ilustrações funcionam para muitas crianças como uma chave para o significado de muitas leituras. Em muitos casos, a imagem complementa e enriquece a história criada pelo autor, a ponto de cada parte da imagem poder gerar diversas histórias.

Contudo, nem sempre foi assim, as ilustrações em literatura infantil eram raras. Arroyo (2011) relata que o primeiro livro ilustrado para crianças decorre do ano de 1744, na Inglaterra: Little pretty pocket-book, de autoria de John Newbery. Somente no século XIX, a literatura infantil se afirmou, com a publicação da coletânea de estórias dos irmãos Grimm, Kinder-und Hausmärchen (Contos para crianças e para a família), no ano de 1812. Não existia uma valorização da imagem, isso era muitas vezes comprovado pela ausência do nome do ilustrador nas obras. Quanto ao percurso literário infantil brasileiro, a imprensa foi quem propagou os primeiros textos literários infantis.

A concepção tradicional de livro prendia-se ao texto escrito, conceito que, infelizmente, permanece até hoje em alguns segmentos de publicação. Indo contra esta corrente tradicional, Werneck (1980) valoriza as ilustrações e as compreende para além do valor estético, elas conferem ao livro o apoio, a pausa e o devaneio tão importantes numa leitura. Em princípio, as imagens 
tinham a função de ilustrar o livro, de mostrar visualmente o que o texto já dizia. Com o passar do tempo, as imagens ganharam um espaço privilegiado, passando a ser produzidas como complementações e não apenas pano de fundo do texto.

Com a evolução da concepção de ilustrações nos livros para crianças, a produção editorial está mais atenta à qualidade, procurando acolher as necessidades do leitor infantil. Para a criação do texto imagético, muitos recursos são utilizados, como colagem, pintura e o auxílio da computação gráfica. Ao pesquisarmos sobre a coleção Paic, prosa e poesia, constatamos que muitos ilustradores trabalham com métodos de representação tradicional, como desenho, pintura, aquarela. Outros trabalham com a criação de imagens completamente digitais. Há exemplos de ilustradores que usam fotografias, xilogravuras, tecidos e estampas para construir as imagens, criando assim uma coleção diversificada e rica em criatividade. Oliveira (2008) reforça que a ilustração criativa permite ao leitor recorrer à imaginação, à fantasia, provocando inúmeras sensações e estimulando múltiplas apreensões.

Devido à grande valorização da literatura infantil cearense e às ilustrações que a compõe, se faz cada vez mais necessário um aprofundamento e um estudo acerca do sistema semiótico das imagens presentes na coleção Paic, prosa e poesia, pois estas imagens poderão estabelecer um vínculo entre o leitor e o livro. Uma melhor compreensão deste processo poderá fornecer estratégias para um maior alcance do público alvo e aprimoramento na qualidade da coleção.

\section{Fundamentação teórica}

A Gramática do Design Visual (doravante GDV) elaborada por Gunther Kress e Theo van Leeuwen, em 1996, emergiu no campo linguístico como uma proposta de análise descritiva e sistemática para estruturas visuais, de modo que atendesse a uma carência teórica analítica que fosse além da conotação, denotação ou iconografia dos níveis de significação das imagens (KRESS; VAN LEEUWEN, 1996).

Essa proposta estabelece um paradigma descritivo dos elementos constituintes de uma imagem, ou seja, constitui uma análise do texto visual, verificando de que forma os componentes internos estão organizados para produzir sentidos em uma determinada mensagem. Nesse sentido, 
os autores adotam a linguagem visual como um sistema de produções de significados, assim como as estruturas gramaticais, visto que exercem funções comunicativas e representacionais em contextos socioculturais.

A GDV foi embasada pela teoria da Linguística Sistêmica Funcional (LSF), que inicialmente foi proposta pelo britânico Michael Halliday, na década de 1950. A LSF concebe a linguagem como uma semiose social, isto é, entende a língua como um sistema estratificado de significados que estão à disposição dos usuários para que esses possam realizar trocas e negociações de sentidos de modo que desempenhem funções em contextos sociais situados.

As três principais funções da linguagem ou metafunções (ideacional, interpessoal e textual) propostas por Halliday (1985), são adotadas por Kress e van Leeuwen (1996) na GDV com outra nomenclatura: representacional (por representar as experiências), interacional (por estabelecer as interações sociais entre os participantes) e composicional (por denotar a organização da estrutura visual e posições ideológicas).

QUADRO 1 - Metafunções

\begin{tabular}{l|l}
\hline \multicolumn{2}{c}{ METAFUNÇÕES } \\
\hline Halliday (1978) & Kress e van Leeuwen (1996) \\
Gramática Sistêmica Funcional & Gramática de Design Visual \\
(Linguagem) & (Imagem) \\
\hline Ideacional & Representacional \\
\hline Interpessoal & Interativa \\
\hline Textual & Composicional \\
\hline
\end{tabular}

Fonte: elaborado pelas autoras.

\subsection{Metafunção representacional}

A metafunção representacional ou ideacional expressa a relação estabelecida entre os participantes (personagens, pessoas, objetos ou lugares) apresentados na estrutura visual. Essa função se subdivide em duas, de acordo com a representação de experiências de mundo vividas pelos participantes da imagem. Caso os participantes estejam interagindo de algum modo entre si, indicando ação, essa imagem é classificada como uma representação narrativa. Contudo, se os participantes representam particularidades de uma categoria, ou características individuais, explicitando uma identidade, ou compartilham traços com os outros participantes da 
imagem, que os identificam como componentes de um grupo, essa relação é classificada como representação conceitual.

Kress e van Leeuwen (1996) categorizam os participantes como interativos, pois são "aqueles que falam, ouvem, escrevem e leem, produzem imagens ou as visualizam", já os representados "são o sujeito da comunicação", ou seja, são aqueles que representam o que foi falado, escrito ou produzido na imagem (KRESS; VAN LEEUWEN, 1996, p. 44).

As representações narrativas indicam processos de ação (acional), reação (reacional), pensamento (processo mental) ou fala (processo verbal). Os processos de ação são indicados por vetores. Segundo Almeida (2009), em cada processo narrativo os participantes são chamados de uma maneira específica. No processo acional, chama-se de ator aquele que está mais em evidência na imagem, que realiza a ação, ou seja, é o elemento da qual parte o vetor, e chama-se de meta o participante alvo da ação, aquele ao qual o vetor se dirige.

Quando uma estrutura narrativa apresenta um ou mais atores conectados com a meta por meio de vetor(es), essa relação é classificada como transacional. Entretanto, quando uma ação apresenta apenas um ator, esse não se direciona para nenhum outro participante, indicando que essa relação é considerada como não-transacional. Segundo Fernandes e Almeida (2008), geralmente, os participantes da ação são apresentados graficamente por um quadrado $(\square)$, todavia a direção do movimento desses é evidenciada por linhas $(-)$ ou pontas de flechas $(\rightarrow)$.

No processo reacional, a ação é indicada pelo olhar. Nesse caso será chamado de reator (observador) aquele participante que está olhando para algo ou alguém, e aquilo que está sendo olhado é chamado de fenômeno, ou seja, o reator dirige seu olhar para um fenômeno. No processo verbal, os participantes são nomeados de dizentes, aqueles que falam, e de enunciado aquilo que foi dito. Já no processo mental há o experienciador (participante) que pensa e exterioriza visualmente seu pensamento, e esse, por sua vez, é considerado fenômeno. Nesse processo o vetor em forma de balão estabelece a relação na imagem.

Para melhor compreensão das classificações, elaboramos a Figura 1, a partir das contribuições de Almeida (2009), que resume as subdivisões presentes na metafunção referencial: 
FIGURA 1 - Subdivisões na metafunção referencial

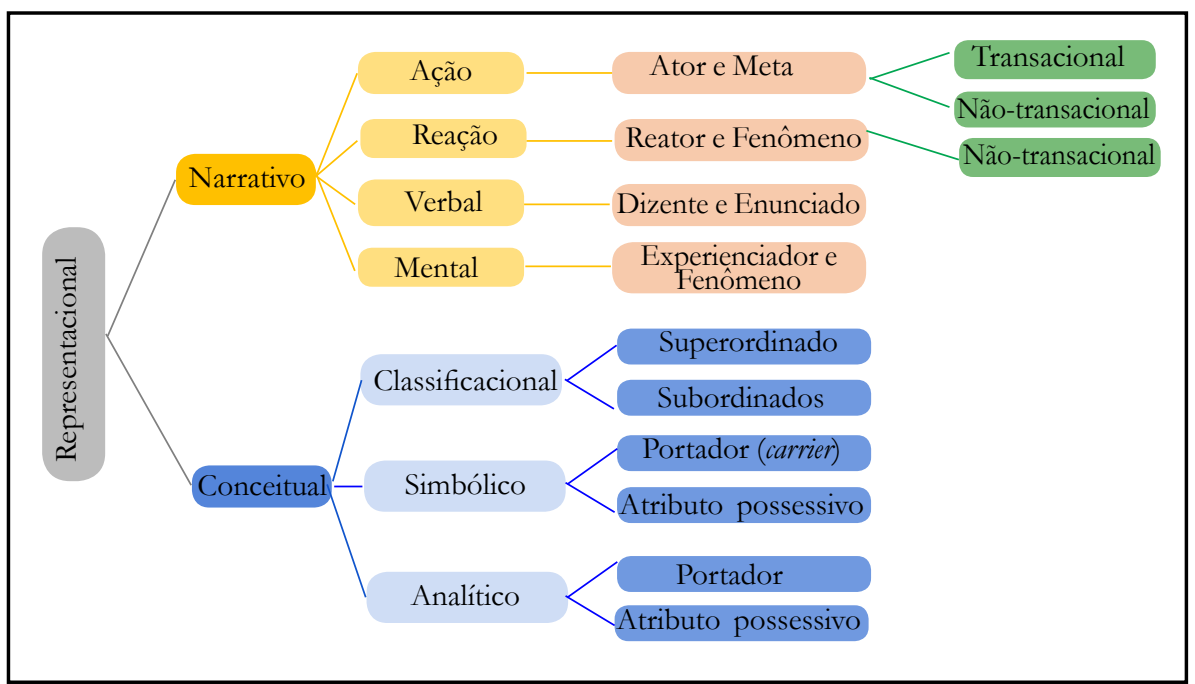

Fonte: elaborada pelas autoras.

Nas representações conceituais não há a presença de vetores, pois os participantes não realizam ações, eles representam conceitos, identidades ou classes. Nessa representação, os participantes, lugares e objetos são analisados, definidos ou classificados. Assim, Kress e van Leeuwen (1996) consideram que as representações conceituais podem ocorrer em processos analítico, simbólico ou classificacional.

No processo classificacional, os participantes fazem parte de uma mesma categoria, pois apresentam características comuns a todos os sujeitos. $\mathrm{Na}$ imagem, os participantes se relacionam com os outros por meio de uma taxonomia hierárquica, onde atuam como subordinados e superordinados. Já no processo simbólico os participantes representam ou são uma identidade que pode ser percebida a partir de propriedades que chamam a atenção, por exemplo a seleção de cores, o tamanho, iluminação, entre outros atributos.

Os participantes desse processo são classificados em portador (carrier) e seus atributos. No processo analítico, os participantes se relacionam através de uma estrutura imagética na qual a(s) parte(s) se relacionam. Os personagens são classificados como portador, aquele que é representado como o todo, e os vários atributos possessivos, que representa as partes do todo (ALMEIDA, 2009; KRESS; VAN LEEUWEN, 1996). 


\subsection{Metafunção interativa}

A metafunção interativa compreende as estratégias pelas quais a estrutura imagética estabelece relações com o leitor/observador por meio da linguagem visual. Kress e van Leeuwen (1996) destacam que as relações entre os participantes do ato comunicativo podem promover aproximação ou afastamento, dependendo do recurso utilizado pelo produtor da imagem, assim, o contato, a distância social, a perspectiva ou atitude e a modalidade são categorias que exercem uma função essencial nessa relação.

O contato estabelecido entre a imagem e o leitor/observador pode ser realizado por meio do olhar do participante da imagem. Caso o olhar deste esteja direcionado para o leitor/observador, teremos uma relação de demanda, que indica que o produtor quer estabelecer uma relação de afinidade com aquele que está lendo a imagem, ou seja, convida o leitor a interagir naquele ato comunicativo. Porém, se na imagem não existir vetor visual direcionado para o leitor, foi estabelecido uma relação de oferta, ou seja, o produtor oferece sua imagem para apreciação.

A distância social estabelece uma relação de intimidade maior ou menor entre a imagem e o leitor, dependendo da altura e das partes do corpo do participante representada(s) na imagem. Quando os participantes são mostrados na imagem dos ombros para cima, o plano é fechado (close-up) e estabelecem uma relação mais íntima com o leitor. Caso a representação imagética for realizada dos joelhos ou da cintura para cima, em plano médio (medium shot), estabelece uma relação social. Quando o participante da imagem é apresentado em um plano aberto (long distance), ou seja, onde é possível ver todo o corpo, representa uma relação impessoal, de distanciamento social.

Na perspectiva ou atitude denota-se a relação do olhar do leitor para a imagem por meio da representação da angulação frontal, oblíqua e vertical. A angulação frontal propõe uma relação mais íntima e igualitária entre o personagem apresentado e o leitor/observador. Já na angulação oblíqua, o participante da imagem apresenta-se de perfil, estabelecendo uma relação de desatenção ou desprezo. $\mathrm{Na}$ angulação vertical, as relações de poder são estabelecidas a partir do posicionamento da captura da imagem.

Essa angulação muito se assemelha com a posição de uma câmera. Há uma relação de superioridade do produtor e do leitor quando a imagem apresenta ângulo alto, isto é, como se a imagem representada fosse tirada de cima para baixo, como se uma câmera estivesse no alto. De acordo com 
Almeida (2009), Kress e van Leeuwen (1996) consideram que se essa relação se inverter e a representação da imagem é feita de baixo para cima, a relação do observador é de inferioridade e quem detém o poder é o participante da imagem.

A modalidade é a terceira e última categoria da metafunção interativa. Nela, o que está em evidência é a modulação da realidade, onde os recursos utilizados interferem nos níveis de verossimilhança da imagem. A linguagem visual pode representar o mundo numa perspectiva mais real, com maior aproximação com a realidade, ou numa perspectiva mais imaginária, fantasiosa.

Os tipos de modalidade estão subdivididos em: naturalista (imagens que mais se aproximam da realidade), sensorial (a imagem é produzida para despertar algum sentimento ou sensação subjetiva), abstrata (imagens que correspondem a representações figurativas e abstrações dos detalhes e focos) e tecnológica/científica (imagens que geralmente são desprovidas de plano de fundo, contextualização, cor e/ou iluminação, assim como as abstratas, entretanto torna-se mais real que as imagens abstratas por apresentar linha técnica incolor, perspectiva ou contextualização).

Há também os mecanismos de modalização que podem ser por meio da utilização da saturação, diversificação ou modulação das cores e sombras. Podem acontecer através da contextualização, que ocorre com a ausência ou detalhamento do cenário. Ou podem ocorrer pelo mecanismo de iluminação ou nível de brilho na imagem (FERNANDES; ALMEIDA, 2008).

A Figura 2 resume as categorias presentes na metafunção interativa. 
FIGURA 2 - Categorias da metafunção interativa

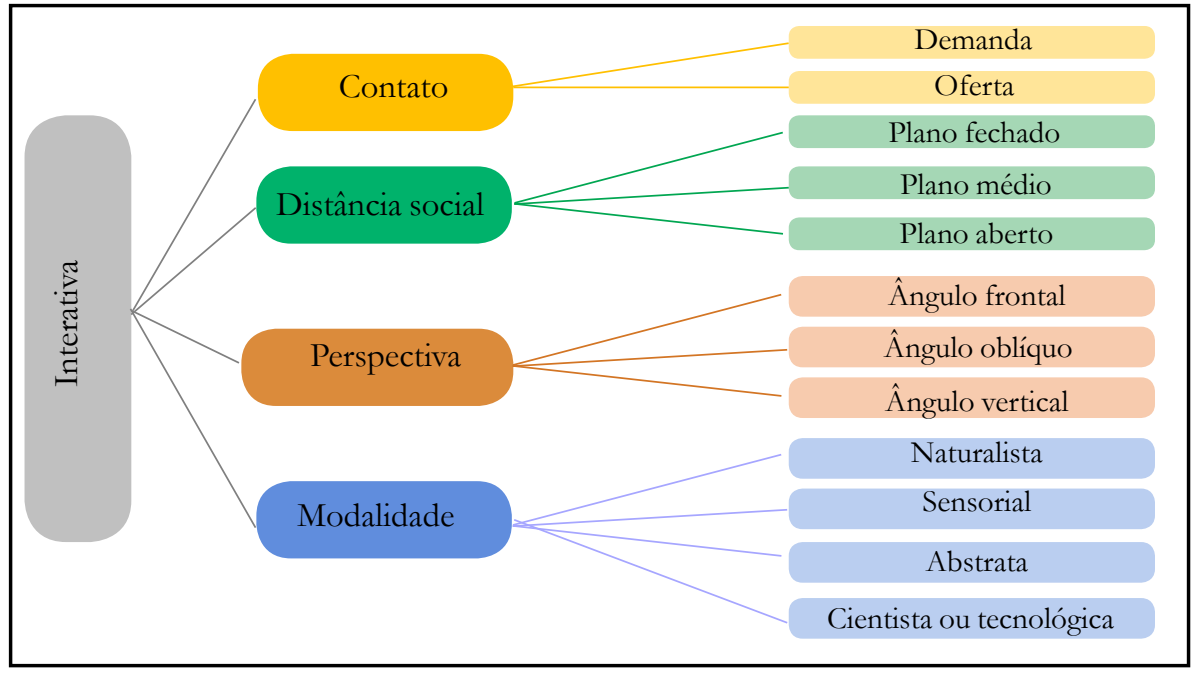

Fonte: elaborada pelas autoras.

\subsection{Metafunção composicional}

Na perspectiva da metafunção composicional, Kress e van Leeuwen (1996) destacam que a estruturação composicional dos elementos presentes no texto visual se organiza para produzir sentido. Essa metafunção agrega as outras duas metafunções, representacional e interativa, para produzir uma imagem harmônica. Os significados gerados pela organização espacial dos elementos podem ser interpretados através dos três sistemas que se interrelacionam: valor de informação, saliência e estruturação.

O valor de informação corresponde ao posicionamento dos elementos que fazem parte da composição visual. Assim, as imagens podem ser polarizadas horizontalmente (direita/esquerda), verticalmente (topo/base) ou centralizadas (centro/margem). Segundo Kress e van Leeuwen (1996), os elementos que estiverem localizados à esquerda indicam o dado, isto é, aquela informação é de conhecimento do leitor/observador ou faz parte do senso comum, e os elementos que estão situados à direita correspondem àquilo que é novo, ou seja, a uma nova informação, algum problema, ou ainda algo que seja desconhecido pelo leitor.

$\mathrm{Na}$ polarização vertical (topo/base), o elemento presente na parte superior da imagem é mais salientada e indica o ideal, aquilo que é idealizado, 
ou uma posição ideológica. Já o elemento que está situado na base, parte inferior da imagem, denota o real, ou seja, é aquilo que está mais próximo da realidade. Segundo os autores da GDV, as imagens também podem estar estruturadas no centro, que representa o núcleo da informação, ou podem estar nas margens, onde estão localizados os elementos que subsidiam a informação central.

Com base nas contribuições de Kress e van Leeuwen (1996), elaboramos a Figura 3, que sintetiza o valor de informação de uma imagem de acordo com a sua posição.

FIGURA 3 - Valor de informação de uma imagem

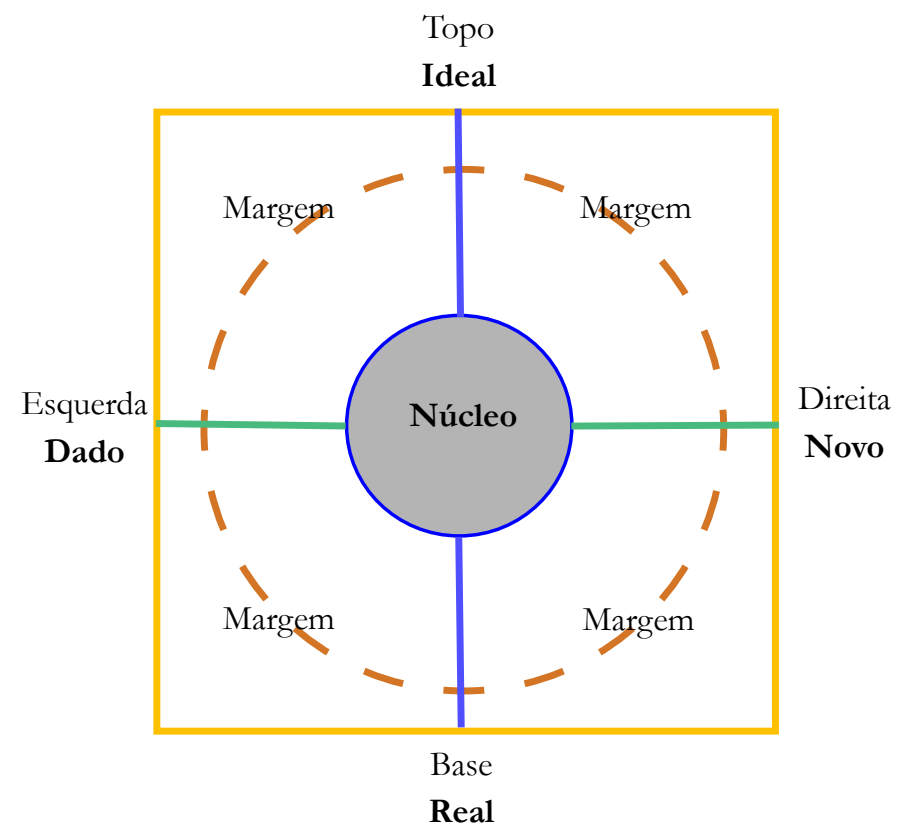

Fonte: elaborada pelas autoras.

Segundo a GDV, a saliência indica atribuição de maior ou menor destaque. Assim, quanto mais saliente o participante for, maior a sua representatividade e importância na imagem, isto é, o elemento que está em primeiro plano tem maior significação do que o que está em segundo plano. A estruturação de imagem emana da forma como os elementos se integram ou não para constituir a unidade de informação. Quando há integração entre os elementos a conexão é feita por uma linha imaginária. 
Resumidamente, podemos apresentar as estruturas básicas da função composicional na Figura 4.

FIGURA 4 - Estruturas básicas da função composicional

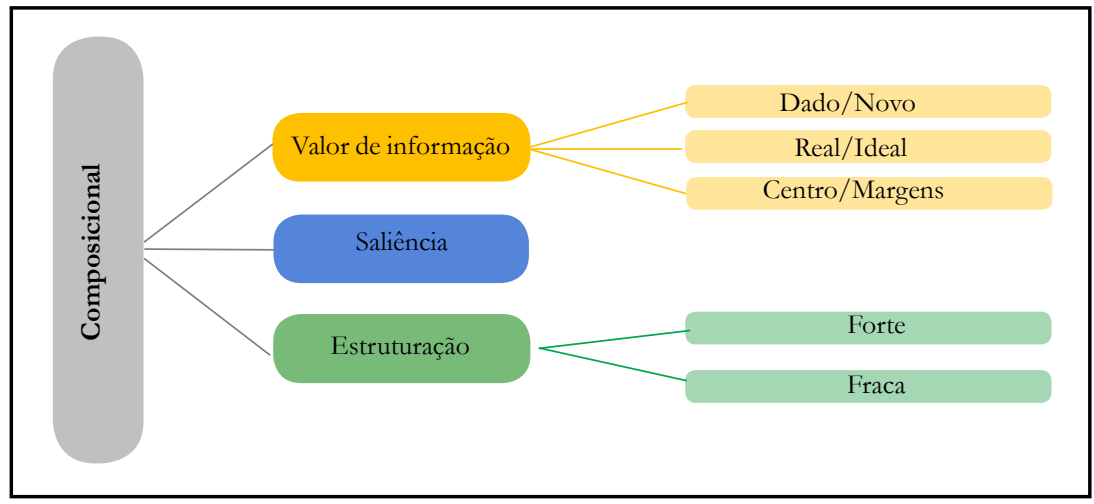

Fonte: elaborada pelas autoras.

\section{Metodologia}

Este artigo analisará as imagens da capa do livro, que compõe a coleção Paic, prosa e poesia, Brincando de inventar, com texto de Neomaly Cavalcante e ilustrações de Emanuel Oliveira. Esse livro faz parte da coleção editada em 2015 e distribuída à rede pública de ensino cearense, no ano de 2016 pela Seduc. A imagem foi analisada mediante a perspectiva da GDV, pois nos permite compreender as composições em seus componentes básicos para entender como os elementos se combinam e conectam para criar sentidos.

Após estudarmos a teoria da multimodalidade de Kress e van Leeuwen (1996) e percebermos que ela pode ser aplicada a qualquer texto multimodal, decidimos analisar a capa de livro infantil, por compreendermos a quantidade de informações que podem ser apreendidas na análise deste texto multimodal, considerando que a capa do livro é o primeiro contato do leitor com a obra. Se esse primeiro encontro for agradável e despertar o interesse, estará consumada a primeira identificação do leitor com o livro.

A capa pode ter um caráter de redundância, caso seja reutilizada uma das ilustrações contidas no corpo da obra. É o que acontece com o livro em questão. $\mathrm{O}$ ilustrador utilizou, em Brincando de inventar, as ilustrações na página 13 (essa é a página central do livro) como capa. Em alguns livros, as ilustrações da capa são diferentes das demais imagens que acompanham o texto. Dependendo do grau de estilização, 
a capa pode tornar-se simbólica, ultrapassando o texto e permitindo uma leitura mais profunda. Nesse caso, no dizer de Silva (2009), ela funciona estilisticamente como uma metáfora.

Para análise, utilizamos gráficos junto à capa com as indicações das classificações, pois torna mais compreensível ao leitor deste artigo. Lembramos que as categorizações foram baseadas na GDV e propostas por Kress e van Leeuwen (1996).

\section{Discussão da análise}

Nessa seção, analisaremos a capa do livro Brincando de inventar, pertencente à coleção Paic Prosa e Poesia, à luz da GDV, proposta por Kress e van Leeuwen (1996), no que se refere às funções representacional, interativa e composicional.

FIGURA 5 - Capa do livro Brincar de inventar

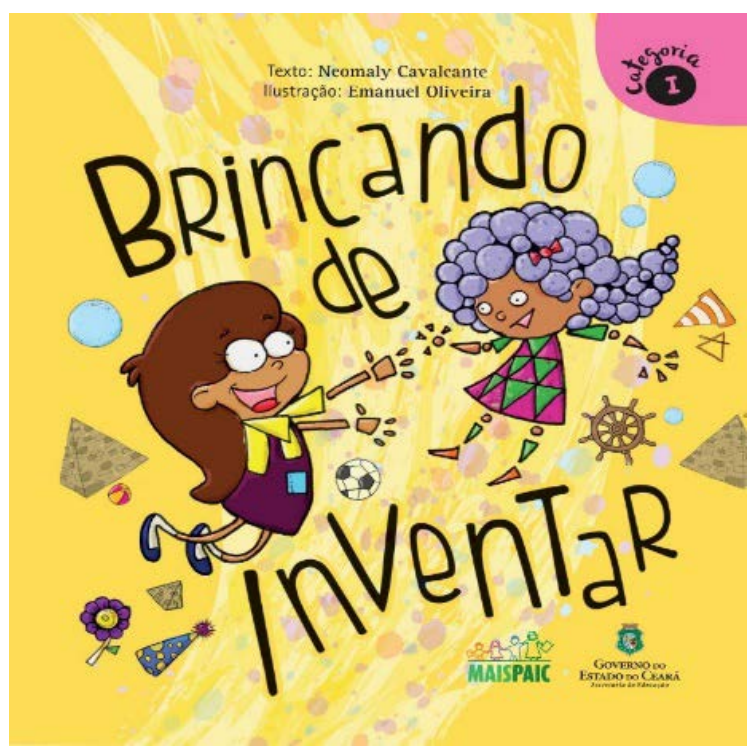

O livro de literatura infanto-juvenil Brincando de inventar narra a história de duas crianças, Alan e Lia, que, por onde passam, usam a imaginação e criam várias distrações, jogos e brincadeiras. Em uma dessas brincadeiras, Lia criou uma boneca com círculos e triângulos. Esse episódio de encontro 
entre a criadora (Lia) e a criatura (a boneca) também está representado na página central do livro.

Os sistemas semióticos (linguagem verbal e visual) que compõem esse texto multimodal representam objetos, lugares e personagens fictícios que são responsáveis pela produção de significados, e por isso são considerados participantes/sujeitos da comunicação. Assim, a capa do livro pode ser considerada um texto multimodal por ser uma representação da linguagem que apresenta um propósito comunicativo, por existir um leitor presumido, por ter um autor/produtor, por necessitar de conhecimento do contexto cultural para a interpretação desse texto e por ter a combinação de mais de um modo semiótico para a construção de significados.

Ao realizarmos a análise da capa do livro na perspectiva da metafunção representacional, verificamos que os participantes visuais apresentados, Lia e a boneca, estão em movimento de ação, na qual Lia é "ator" da ação por estar em maior evidência na imagem e por estar indo de encontro à boneca (meta) de forma que deseja pegá-la ou alcançá-la. A boneca é a "meta" por ser o participante alvo da ação, portanto, aquela em que o vetor (ação) está se dirigindo. Diante do exposto, podemos considerar essa capa como uma estrutura narrativa de ação transacional, pois ocorre ação dos personagens apresentados, em que o ator (Lia) está conectado com a meta (boneca) por meio de vetor (ação de olhar).

$\mathrm{Na}$ análise da interação da estrutura visual, ou seja, da metafunção interativa, há uma relação de distanciamento social entre o produtor do texto e o leitor/observador. Ainda tomando por base essa metafunção, podemos afirmar que em relação ao contato a imagem da capa do livro é de oferta, pois as personagens não direcionam seus olhares para o leitor/observado, assim a imagem está sendo ofertada para contemplação e não para interação. A distância social é representada em um plano aberto, na qual vê-se todo o corpo das participantes, expressando assim um distanciamento do leitor/ observador. Acreditamos que esse distanciamento proposital presente na composição da capa objetiva deixar o leitor/observador mais livre para usar sua imaginação e criatividade para a leitura do texto imagético, de forma que esses construam seus próprios significados a partir dos seus contextos históricos, sociais e culturais.

A perspectiva foi estabelecida em ângulo frontal, como se um fotógrafo tivesse capturado ou registrado a imagem dos personagens de frente, mas vale destacar que a composição imagética apresenta um grau 
elevado de complexidade, pois por mais que o ângulo seja frontal e de atitude igualitária, nota-se que as personagens (Lia e a boneca) apresentam uma certa inclinação em seus corpos como estivessem flutuando.

A modalização da imagem foi realizada por meio da utilização diversificada de cores e de formas geométricas que compuseram as ilustrações para poder chamar a atenção do leitor infantil. Vale destacar que a boneca criada foi toda construída com círculos e triângulos, possibilitando ao professor utilizar esse material de literatura durante as aulas de matemática, promovendo uma interdisciplinaridade, conforme recomenda-se na Base Nacional Comum Curricular (BRASIL, 2017).

Sob a perspectiva composicional, analisamos de que forma os elementos presentes no texto visual se organizam para produzirem sentido. Quanto ao valor de informação correspondente ao posicionamento dos elementos, podemos verificar que as personagens estão no centro da capa, e horizontalmente polarizadas. No lado direito está a personagem Lia, representando a informação dada, e no lado esquerdo encontra-se a boneca, a personagem nova, criada.

Ao redor das personagens que estão em primeiro plano e com maior saliência, ou seja, nas margens, há objetos que também representam figuras geométricas. Destacamos ainda que a estruturação dessa linguagem visual é realizada por meio da inter-relação das cores, de luminosidade, pois o centro é mais claro do que as margens e os objetos presentes na imagem (formas geométricas), e por meio do vetor conector entre a garota e a boneca, como pode ser visto na Figura 6, capa do livro Brincando de inventar e no quadro que sintetiza as análises. 
FIGURA 6 - Capa do livro e síntese das análises

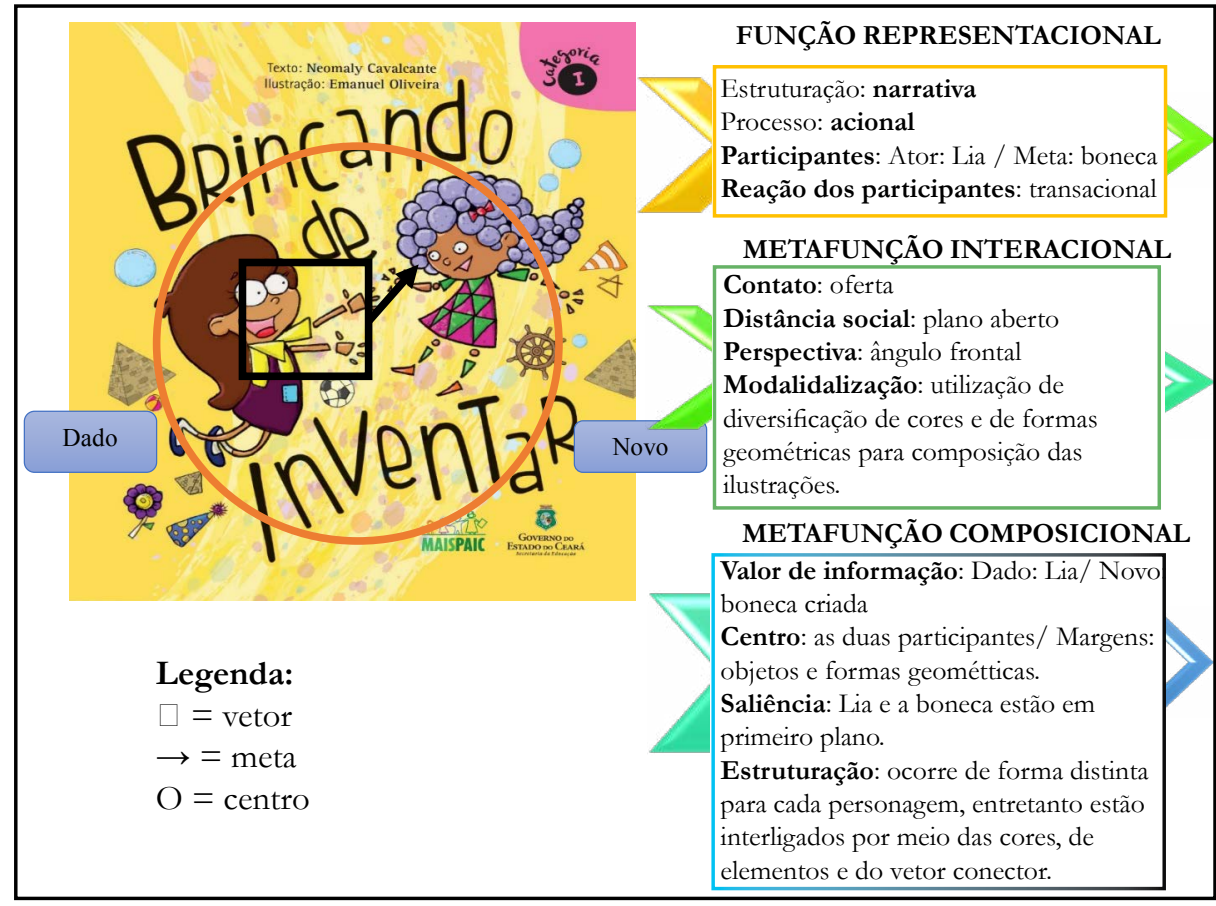

Fonte: elaborado pelas autoras.

Diante da análise aqui apresentada, percebemos que os recursos usados na composição da capa revelam uma preocupação com o leitor/ observador. Em volta das personagens principais que estão apresentadas para contemplação, há elementos que são do universo infantil, como o chapéu de aniversário, a flor, as bolas, as uvas, os cones, entre outros elementos que têm a função de convidar o leitor para o primeiro contato com o livro, para o processo de alfabetização, por meio da leitura multimodal e da leitura literária.

A capa de um livro, principalmente voltado ao público infantil, assume um papel privilegiado na comunicação com o pequeno leitor. As imagens presentes na capa, por vezes, são divertidas, atrativas e descompromissadas, proporcionando estímulos à curiosidade e ao interesse para prosseguir na leitura do livro. Assim, conforme Paiva (2008), a literatura infantil cumpre papel fundamental no processo de escolarização, contribuindo de forma decisiva para a formação do futuro leitor, especialmente o leitor literário, 
podendo vir a apreciar, a qualquer momento de sua vida, a literatura como experiência estética, proporcionada por essa manifestação artística que, muitas vezes, inicia com a capa do livro.

Ao ouvir mensagens (histórias) em contextos significativos, ao ver as imagens presentes nos livros, a criança insere-se no processo de construção da linguagem, diferente do processo de simples domínio de codificação e decodificação de sentenças descontextualizadas. O livro infantil, portanto, viria a contribuir para este processo de construção da linguagem e, por seguinte, proporcionar a formação de leitores iniciais. Maia (2007) sugere ainda que os diálogos e os comentários sobre leituras realizadas tanto pelos professores quanto pelos alunos são necessários para que haja troca de informações, confronto de opiniões, comunhão de ideias, exposição de valores, conduzindo ao desenvolvimento dos sujeitos envolvidos.

Para tanto, os textos literários destinados aos alunos devem suscitar o prazer estético, aguçar a criticidade do pequeno leitor, ampliando os olhares para a realidade, conforme afirma Oliveira (2008). Dessa forma, as obras literárias precisam ser efetivamente exploradas no contexto escolar. Para tal, o encontro do aluno com o texto literário na escola deve iniciar a partir da leitura, que pode acontecer em sala de aula, biblioteca ou em outros ambientes escolares.

De acordo com a pesquisa de mestrado realizada por Araújo (2018), que tinha como um de seus objetivos averiguar as percepções dos alunos cearenses do $2^{\circ}$ ano do Ensino do Fundamental I sobre a literatura infantil (coleção Paic, prosa e poesia), um dos livros mais apreciados pelos discentes era o Brincando de inventar. Entre alguns motivos citados pelos alunos e apresentados na pesquisa encontra-se a temática voltada para a infância e vocábulos associados ao contexto do dia a dia das crianças. Além disso, a pesquisadora relata que os livros da referida coleção estabelecem uma dupla relação: do leitor com os personagens e destas com o leitor. Para o início desta dupla relação, conforme observado na pesquisa de campo, a professora das crianças apresenta o livro: a capa, o nome da autora e do ilustrador e segue para a prática literária da contação de história.

O livro, que é destinado ao público da educação infantil, convida esse novo leitor a aprender por meio da ludicidade, das cores, da imaginação, de objetos e imagens que se fazem presente cotidianamente ou até mesmo no contexto escolar (como é o caso das formas geométricas), despertando nele vários processos internos de desenvolvimento. Esses processos promovem 
o reconhecimento e a aprendizagem por meio das interações realizadas durante o contato com aquele texto multimodal.

Queremos destacar que essa interação entre leitor e obra ultrapassa a leitura aqui proposta pela GDV, tendo em vista que as imagens aqui analisadas produzem sentidos ímpares para cada leitor(a), para cada comunidade, contextos e para cada cultura. O sentido de uma leitura não pode ser unívoco, bem como as possibilidades de leitura também não podem ser esgotadas.

\section{Considerações finais}

Ao analisarmos as imagens da capa do livro Brincando de inventar, que compõe uma das coleções Paic, prosa e poesia, tivemos como base a GDV, de orientação sistêmico funcional. No decorrer da nossa análise, percebemos o quanto o texto imagético, como recurso pedagógico, pode atrair atenção do leitor e valorizar a identificação deste com texto apreciado.

Durante nossa pesquisa, percorremos um terreno fértil dos estudos da imagem como um campo de pesquisa científica, em que ressaltamos a importância de analisar as ilustrações presentes nos livros infantis. Detivemonos na capa do livro por ser o primeiro contato do leitor com a obra literária. O que descrevemos nos forneceu um aparato para o desenvolvimento de habilidades de leitura e construção de textos multimodais. Nesse sentido, nosso trabalho traz uma contribuição para se entender textos multimodais na perspectiva da semiótica visual e consolidação da teoria da multimodalidade em imagens, presentes no gênero literário, que circulam nas escolas e utilizam a literatura infantil para propiciar a formação de leitores.

Reforçamos que não se esgotaram com o nosso artigo as possibilidades de análise da capa do livro Brincando de inventar. Assim, estamos cientes que existem outras visões para além da GDV, da visão de verdade por meio da representatividade das imagens. Afinal, estas podem representar, mas também podem construir significados que são reconstruídos contextualmente, o que pode acontecer durante a prática de contação de história ou pela vivência dos leitores que encontram afinidade com a temática abordada no texto literário.

A escolha pela literatura infantil nos motivou, por acreditarmos que esta contribui para a alfabetização estético-visual das crianças e é de grande valia na formação da sensibilidade e do pensamento da criança em sua vivência de mundo, afinal, os livros com ilustrações possibilitam à criança 
sonhar, imaginar. Podem provocar alegria, comoção, paixão, encanto, entre outros sentimentos, fazendo com que a criança dê significados especiais àquelas imagens.

Ressaltamos, assim, que é necessário compreendermos que as imagens não se constituem apenas como suportes para textos verbais, porém são imensamente carregadas de sentidos, como analisamos no artigo. Desta forma, como pesquisadoras da linguagem e professoras nos cabe também voltarmos para o estudo da elaboração da imagem e das leituras proporcionadas a partir das imagens para promovermos um diálogo entre a teoria e a prática, a fim de trabalharmos com estruturas imagéticas em sala de aula.

\section{Contribuição das autoras}

Este artigo foi amplamente discutido e escrito pelas três autoras, porém cada pesquisadora realizou contribuições específicas. Lya Oliveira da Silva Souza Parente desenvolveu o Resumo, Fundamentação teórica e Discussão da análise. Já Sammya Santos Araújo desenvolveu o Abstract, Introdução, As ilustrações na coleção Paic, prosa e poesia, Metodologia e Considerações finais. Por fim, a professora doutora Antonia Dilamar Araújo foi a responsável por toda orientação e revisão estrutural e conceitual da pesquisa. No decorrer da escrita, fizemos leituras e ajustes que permitiram às autoras o desenvolvimento integral do artigo.

\section{Referências}

ALMEIDA, D. B. L. Do texto às imagens: as novas fronteiras do letramento visual. In: PEREIRA, R. C.; ROCA, P. (org.). Linguística Aplicada: um caminho com diferentes acessos. São Paulo: Contexto, 2009. p. 173-202.

ARAÚJO, S. S. A formação de leitores iniciais e o letramento literário em uma turma do $2^{\circ}$ ano do ensino fundamental I atendida pelo Programa Aprendizagem na Idade Certa (MAIS PAIC). 2018. 127f. Dissertação (Mestrado em Linguística Aplicada) - Programa de Pós-Graduação em Linguística Aplicada, Centro de Humanidades, Universidade Estadual do Ceará, Fortaleza, 2018.

ARROYO, L. Literatura infantil brasileira. 3. ed. São Paulo: Unesp, 2011.

BRASIL. Ministério da Educação. Base Nacional Comum Curricular. educação é a base. Terceira versão. Brasilia, DF: MEC, 2017. Disponível em: http://basenacionalcomum. mec.gov.br/download-da-bncc. Acessado em: 21 maio 2018. 
CAVALCANTE, N.; OLIVEIRA, E. Brincando de inventar. Fortaleza: Seduc, 2015. (Coleção Paic Prosa Poesia).

CEARÁ. Secretaria da Educação. Regime de colaboração para a garantia do direito à aprendizagem: o Programa Alfabetização na Idade Certa (PAIC) no Ceará. Fortaleza: Seduc, 2012.

FERNANDES, J. D. C.; ALMEIDA, D. B. L. Revisitando a gramática visual nos cartazes de guerra. In: ALMEIDA, D. B. L. (org.). Perspectivas em análise visual: do fotojornalismo ao blog. João Pessoa: Editora da UFPB, 2008. p. 11-31.

HALLIDAY, M. A. K. An introduction to Functional Grammar. Londres: Edward Arnold, 1985.

HALLIDAY, M. A. K. Language as social semiotic. Londres: Arnold, 1978.

KRESS, G.; Van LEEUWEEN, T. Reading images: the grammar of visual design. London: Routledge, 1996.

MAIA, J. Literatura na formação de leitores e professores. São Paulo: Paulinas, 2007. (Coleção Literatura \& Ensino).

OLIVEIRA, M. A. A literatura para criancas e jovens no Brasil de ontem e de hoje: caminhos de ensino. São Paulo: Paulinas, 2008. (Coleção Literatura \& Ensino).

PAIVA, A. et al. (org.). Leituras literárias. discursos transitivos. Belo Horizonte: Ceale: Autêntica, 2008.

SILVA, V. M. T. Leitura literária \& outras leituras: impasses e alternativas no trabalho do professor. Belo Horizonte: RHJ, 2009.

Data de submissão: 05/11/2018. Data de aprovação: 21/05/2019. 